\title{
Congenital Melanocytic Nevus Regression Lacking the Halo Phenomenon: The Influence of the Body Site
}

\author{
Maristela Garcia Bassotto de Andrade ${ }^{1}$, Giuseppe Argenziano², Vincenzo Piccolo², Eugenia Veronica \\ Di Brizzi², Elvira Moscarella²
}

\begin{abstract}
1Dermoscopy Fellow, University of Campania “L. Vanvitelli”, Naples, Italy
2Dermatology Unit, University of Campania “L. Vanvitelli”, Naples, Italy
\end{abstract}

Key words: Congenital melanocytic nevus, spontaneous regression, children, involution of nevus, pediatric dermatology, dermoscopy.

Citation: De Andrade MGB, Argenziano G, Piccolo V, Di Brizzi EV, Moscarella E. Congenital melanocytic nevus regression lacking the halo phenomenon: the influence of the body site. Dermatol Pract Concept. 2021; 11(3): e2021028. DOI: https://doi.org/10.5826/dpc.1103a28

Accepted: September 29, 2020; Published: July 8, 2021

Copyright: $\odot 2021$ De Andrade al. This is an open-access article distributed under the terms of the Creative Commons Attribution License BY-NC-4.0, which permits unrestricted noncommercial use, distribution, and reproduction in any medium, provided the original authors and source are credited.

Funding: None.

Competing interests: The authors have no conflicts of interest to disclose.

Authorship: All authors have contributed significantly to this publication.

Corresponding author: Maristela Garcia Bassotto de Andrade, Dermoscopy Fellow at “L. Vanvitelli” University of Campania, Italy. Email:marisgba@hotmail.com

\section{Introduction}

Regression of congenital melanocytic nevus (CMS) has been reported, mainly associated with an immunological mechanism and with the occurring halo phenomenon (a depigmentation zone appearing around the nevus). According to Tokura et.al (as cited in Kageshita, 2003) CD8 T-cell mediated immunity and IgM antibodies may be involved in immunological mechanism of regression [1]. The spontaneous or idiopathic regression of a congenital nevus is uncommon and seems to be most frequent when localized at the level of the palmoplantar region $[1,2]$.

\section{Case Presentation}

Here we report a case of a 6-year-old male, presenting a lesion on the second finger of the right foot that appeared at birth. Clinically, it presented as a $1 \mathrm{~cm}$ diameter nodule, characterized by a heterogeneous brownish color, a hypo-pigmented raised area at the center, and well-defined borders (Figure
1A). When analyzed through dermoscopy, the lesion showed a peripheric reticular pattern with parallel furrows pattern visible on 1 side of the lesion. In the central-nodular area, the presence of multiple grayish dots and globules over a pinkwhite background was detected (Figure 1B).

The lesion was monitored over 3 years. It did not vary in size, but underwent dramatic pigmentation changes (Figure 1C), turning color to light brown, both at the periphery and in the center (Figure 1D).

\section{Conclusion}

CMN may regress in a variety of ways. Ciampo et al. [2] described several distinct mechanisms including trauma, the presence of the depigmentation halo, desmoplasia or even regression without any of the mentioned modalities, which was called idiopathic.

Although idiopathic regression is uncommon, Kageshita (2003) [1], reported on 2 cases of complete CMN spontaneous regression, in the palmar region of 2 Japanese girls. 


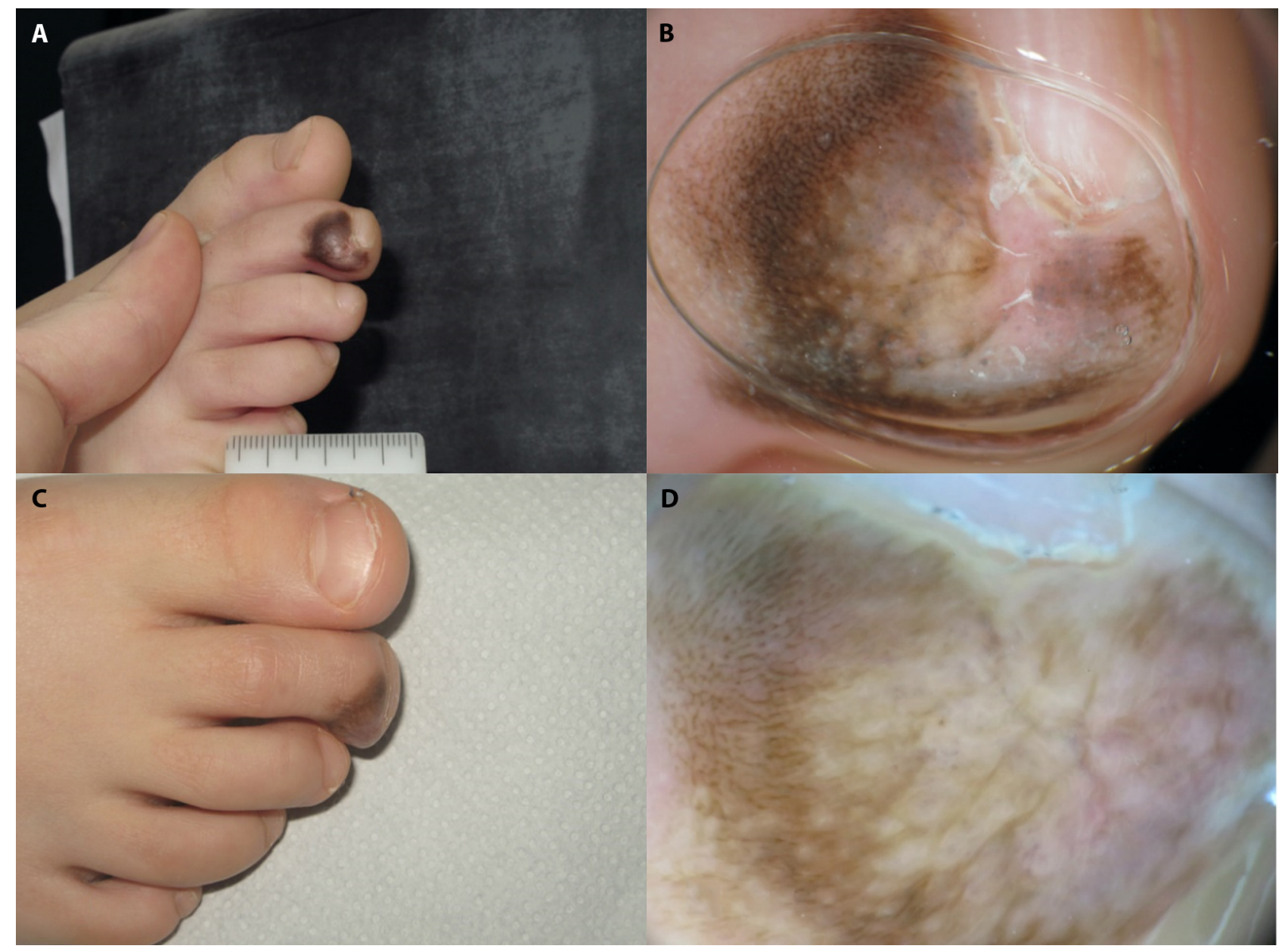

Figure 1. (A) Brownish papule with a heterogeneous color measuring about $1 \mathrm{~cm}$ located on the second toe of the right foot. (B) On dermoscopy, the lesion showed a reticular and a parallel furrows pattern at the periphery. In the central-nodular region, multiple grayish dots and globules over a pink-white background were visible. (C) Clinical lightening of the lesion after 3 years. (D) The lesion appeared cleared in color, both peripherally and in the center.

Despite the absence of a histopathological confirmation, the author concluded that there might be a regression mechanism unrelated to autoimmune issues. According to the statistical analysis carried out by Ciampo et al [2], it was observed that the probability of regression in a congenital nevus located in the palmar and plantar region is 4.95 times greater than in other locations.

Our patient presented a clearing of the lesion color with no evidence of other mechanisms, suggesting a stop in pigment production by the nevus as a regression mechanism, as it occurred in the above-mentioned cases. Moreover, the location of the lesion supports the hypothesis that the palmoplantar location is relevant in the spontaneous regression pro- cess. Our report lacks histopathologic examination results, therefore larger case series supported by histopathologic examination are necessary.

\section{References}

1. Kageshita, Toshiro \& Inoue, Yuji \& Ono, Tomomichi. Spontaneous Regression of Congenital Melanocytic Nevi without Evidence of the Halo Phenomenon. Dermatology (Basel, Switzerland). 2003; 207:193-5. DOI: 10.1159/000071794. PMID: 12920373

2. Ciampo L, Milano A, Colonna V, Bonifazi E. Prevalence of spontaneous regression in congenital melanocytic nevus. Eur. J. Pediat. Dermatol. 2008; 18 (3): 164-173.Retrieved from https:// www. ejpd.com/journal/index.php/EJPD/article/view/492. 